\title{
Prototipe Pembatas Biaya Daya Listrik pada Skala Rumah Tangga Berbasis Mikrokontroler
}

\author{
Toman Hendra Lumban Gaol, Dikpride Despa, Noer Sudjarwanto \\ Jurusan Teknik Elektro Universitas Lampung \\ Jl. Prof. Sumantri Brojonegoro No. 1 Bandar Lampung 35145 \\ toman0marbun@gmail.com
}

\begin{abstract}
ABSTRAK
Penggunaan energi listrik yang tidak terkontrol dapat menyebabkan tagihan yang dibayar ke PLN cukup mahal. Hal tersebut dapat disebabkan karena kelalaian atau lupa untuk mematikan peralatan yang tidak perlu dipakai. Untuk mencegah pemakaian energi yang berlebih maka dibutuhkan alat untuk memutus biaya listrik sesuai dengan biaya diinginkan yang dapat menampilkan biaya pemakaian listrik agar dapat mengetahui kisaran biaya untuk menghemat pemakaian listrik tersebut.

Tugas akhir ini membuat sebuah alat yang dapat menampilkan pemakaian biaya listrik dan memutus penggunaan listrik sesuai biaya yang diinginkan dengan menggunakan Mikrokontroler sebagai pengendali utama. Program untuk pengendali mikrokontroler dibuat dengan bahasa C. Komponen utama sebagai input mikrokontroler adalah keypad sebagai inputan biaya listrik dan sensor arus untuk mendeteksi besarnya arus pada beban. Komponen utama sebagai output adalah Liquid Chrystal Display (LCD) sebagai informasi pemakaian biaya listrik dan relay untuk memutus beban. Prototipe pembatas biaya listrik otomatis ini dapat bekerja dengan baik menampilkan besarnya arus dan pemakaian daya yang terpakai serta memutus pemakaian listrik apabila telah sesuai dengan biaya listrik yang ingin dibatasi.
\end{abstract}

Kata kunci : Prototipe pembatas daya listrik, Keypad, Liquid Chrystal Display, Mikrokontroler, Relay.

\section{ABSTRACT}

The use of uncontrolled electrical energy can cause the bills paid to PLN is quite expensive. It can be caused due to negligence or forgot to turn off unnecessary equipment wear. To prevent excess electrical energy consumption needed a tools to disconnect electricity cost in accordance with the desired cost that can display costs in electricity use in order to find out the range of costs to save power consumption.

The undergraduate thesis is to create a tool that can display the usage costs of electricity and disconnect electricity use according the desired cost by using a microcontroller as the main controller. Microcontroller to control the programs created with the $\mathrm{C}$ language. Major components as inputs the microcontroller is the keypad as input costs electricity and current sensors to detect the magnitude of the current in the load, while the output of microcontroller used Liquid Chrystal Display (LCD) as the cost of electricity consumption information and relay to disconnect the load. A prototype delimiter electricity cost automatic can work properly showing the amount of current and power consumption that is unused and disconnect electricity use when were in accordance with the cost of electricity to restricted.

Keyword : Prototype delimiter electricity cost, keypad, Liquid Chrystal Display, Microcontroller, Relay

\section{PENDAHULUAN}

Kebutuhan listrik setiap tahun akan meningkat seiring dengan bertambahnya jumlah penduduk dan bertambahnya industri. Pemborosan penggunaan energi listrik pada rumah tangga disebabkan penggunaan peralatan listrik yang cenderung berlebihan, kurang tepat dalam pemakaiannya dan kelalaian dalam mematikan peralatan listrik yang tidak dipakai. Pemakaian listrik pada rumah tangga diketahui dengan membaca pemakaian daya (kWh) pada rumah tangga. Semakin besar pemakaian daya listrik maka semakin besar juga biaya yang harus dibayarkan ke PT. PLN. Untuk mencegah pemakaian daya yang berlebih maka dibutuhkan alat untuk memutus pemakaian listrik sesuai dengan biaya daya listrik yang diinginkan dan dapat juga menampilkan pemakaian arus dan biaya listrik yang sedang berlangsung.

Mikrokontroler dapat digunakan sebagai pengendali alat pembatas biaya listrik yang dapat 
membatasi biaya yang diinginkan agar dapat melakukan pengontrolan dengan memperkirakan biaya yang diinginkan. Mikrokontroler merupakan suatu chip berupa IC (Integrated Circuit) yang dapat menerima sinyal input, mengolahnya dan memberikan sinyal output sesuai dengan program yang diisikan ke dalamnya. Mikrokontroler pada dasarnya adalah komputer dalam satu chip, yang di dalamnya terdapat mikroprosesor, memori, jalur Input/Output (I/O) dan perangkat pelengkap lainnya.

Mikrokontroler mempunyai fungsi Analog to Digital Converter (ADC) yang digunakan dalam mendeteksi sensor arus, Timer/Counter untuk perhitungan waktu dalam menghitung $\mathrm{kWh}$ dan biaya listrik yang digunakan, saluran I/O sebanyak 32 buah untuk masukan keypad sebagai media memasukkan biaya listrik dan LCD sebagai keluaran untuk menampilkan informasi arus, biaya listrik dan pemakaian $\mathrm{kWh}$ lisrik yang sedang berlangsung.

\section{TINJAUAN PUSTAKA}

\subsection{Daya Listrik}

Daya listrik merupakan perkalian antara tegangan dan arus pada beban. Berdasarkan keadaan arus dan tegangan yang terdapat pada rangkaian, daya dapat digolongkan dua macam yaitu:

1. Daya dalam rangkaian arus searah.

2. Daya dalam rangkaian arus bolak-balik.

Daya yang terdapat dalam tahanan yang dialiri oleh arus searah (DC) dituliskan dengan rumus [1] :

$$
P=V . I=\frac{V^{2}}{R}=I^{2} R
$$

Sedangkan daya pada impedansi yang dialiri arus bolak balik (AC) terdiri dari [2] :

\section{Daya Aktif}

Daya aktif adalah daya yang terpakai untuk melakukan energi sebenarnya. Satuan daya aktif adalah Watt.

Daya aktif dinyatakan dengan rumus :

$$
P=V \times . I \times \operatorname{Cos} \varphi
$$

2. Daya Reaktif.

Daya reaktif merupakan daya yang terpakai sebagai energi pembangkitan medan magnetik sehingga timbul fluks magnetik. Satuan daya reaktif adalah Volt Ampere Reaktif (VAR). Daya reaktif dinyatakan dengan rumus :

$Q=V \times I \times \operatorname{Sin} \varphi$

3. Daya Semu.

Daya semu merupakan daya yang diberikan kepada konsumen atau gabungan penjumlahan trigonometri daya nyata dan daya reaktif. Satuan daya semu adalah Volt Ampere (VA). Daya semu dinyatakan dengan rumus :

$$
S=V \times I
$$

\subsection{Biaya listrik}

Biaya listrik adalah biaya yang harus dibayarkan oleh pelanggan kepada PLN sesuai dengan pemakaian energi listrik. Menghitung pemakaian biaya listrik dinyatakan dengan rumus [3] :

Biaya Listrik $=$ Pemakaian $(\mathrm{kWH}) \times$ Tarif Tenaga Listrik

Daya dapat didefenisikan sebagai kecepatan atau kemampuan melakukan usaha dalam satuan waktu [1]. Daya dinyatakan dengan rumus :

$$
\mathrm{P}=\frac{\mathrm{W}}{\mathrm{t}}
$$

Keterangan :

$$
\begin{array}{ll}
\mathrm{P} & =\text { Daya }(\text { Watt }) \\
\mathrm{W} & =\text { Energi }(\text { Joule }) \\
\mathrm{t} & =\text { Waktu }(\mathrm{s})
\end{array}
$$

Dari persamaan diatas, didapatkan hubungan :

$1 \mathrm{Watt}=1 \mathrm{Joule} / \mathrm{detik}$

Artinya 1 Watt adalah besarnya daya ketika enegi sebesar 1 Joule dibebaskan dalam 1 detik.

$\mathrm{kWh}$ adalah energi yang digunakan selama pemakaian dalam satu jam. $\mathrm{kWh}$ dinyatakan dengan rumus [2]:

$W h=P x t(j a m)$

$W h=V \times I \times \cos \varphi \times t(j a m)$

$k W h=\frac{V \times I}{1000} \times \cos \varphi \times t(j a m)$

\subsection{Tarif Tenaga Listrik}

Tarif tenaga listrik adalah tarif tenaga listrik untuk konsumen yang disediakan oleh perusahaan (Persero) PT. Perusahaan Listrik Negara [3]. 
Berdasarkan cara pembayaran, tarif tenaga listrik dibagi dua jenis yaitu :

1. Tarif tenaga listrik reguler.

Tarif tenaga listrik reguler merupakan tarif tenaga listrik yang dibayarkan setelah pemakaian tenaga listrik oleh konsumen.

2. Tarif tenaga listrik prabayar.

Tarif tenaga listrik prabayar merupakan tarif tenaga listrik yang dibayarkan sebelum pemakaian tenaga listrik oleh konsumen.

\subsection{Mikrokontroler}

Mikrokontroler merupakan suatu perangkat elektronika digital berupa IC (Integrated Circuit) yang dapat menerima sinyal input, mengolahnya dan memberikan sinyal output yang dikendalikan oleh program yang bisa ditulis dapat dihapus secara khusus. Mikrokontroler pada dasarnya adalah komputer dalam satu chip, yang di dalamnya terdapat mikroprosesor, memori, jalur Input/Output (I/O) dan perangkat pelengkap lainnya.

Pada tugas akhir ini digunakan salah satu jenis mikrokontroler keluarga AVR (Alf and Vegard's Risc Processor) yang diproduksi oleh Atmel Corporation dikarenakan mikrokontroler ini memiliki fitur-fitur menarik dan fasilitas yang lengkap selain mudah didapatkan dan harga relatif murah.

Mikrokontroler ini merupakan seri mikrokontroler vCMOS 8-bit buatan Atmel yang memiliki daya rendah dalam pengoperasiannya dan berbasis pada arsitektur RISC (Reduced Instruction Set Computer). Hampir semua instruksi dieksekusi dalam satu siklus clock, dan dapat mencapai 1 MIPS per MHz, sehingga para perancang dapat mengoptimalkan penggunaan daya rendah dengan kecepatan yang tinggi. Mikrokontroler ini mempunyai 32 register general purpose, timer/counter fleksibel dengan mode compare, interrupt internal dan eksternal, serial UART, programmable Watchdog Timer, dan mode power saving. Memiliki ADC dan PWM internal, memiliki In-System Programmable Flash on-chip yang mengijinkan memori program untuk diprogram ulang dalam sistem menggunakan hubungan serial SPI.

\subsection{Sensor Arus}

Sensor arus bekerja untuk mendeteksi dan mengukur besaran arus AC pada beban yang digunakan untuk mengukur besaran arus yang masuk pada mikrokontroler.

Prinsip kerja dari rangkaian sensor arus ini adalah dengan arus yang mengalir pada $I C$ tersebut maka akan timbul medan magnet, medan magnet inilah yang nantinya akan digunakan sebagai olahan dari komponen-komponen yang ada didalam IC. Medan magnet yang timbul akibat arus yang mengalir adalah berbanding lurus. Semakin besar arus yang mengalir maka medan magnet yang ditimbulkan semakin besar pula. Pada bagian IC ini terdapat 2 bagian yang berbeda, bagian yang pertama adalah bagian tegangan tinggi 220 Volt AC dan bagian yang kedua adalah bagian tegangan rendah 5 Volt DC. Keluaran dari sensor arus ini adalah tegangan DC yang nantinya akan diolah oleh mikrokontroler. [4].

\subsection{Keypad}

Keypad merupakan perangkat yang tersusun dari tombol yang membentuk matriks (baris $\mathrm{x}$ kolom). Keypad diperlukan untuk membuat pengaturan dengan titik setel akan kontrol umpan balik pada saat program masih berjalan. Gambar 2.6 adalah gambar keypad.

\subsection{LCD}

LCD (liquid Crystal Display) adalah kristal cair yang digunakan sebagai modul tampilan informasi dengan menggunakan tegangan listrik untuk mengubah bentuk-bentuk kristal-kristal cairnya sehingga membentuk simbol, angka dan atau huruf pada layar.

\subsection{Relay}

Relay digunakan untuk memutus dan menghubungkan aliran arus listrik pada beban. Relay bekerja untuk memutus arus searah dan tegangan bolak-balik. Untuk memutus tegangan bolak-balik dibutuhkan relay yang mampu bekerja dengan arus yang tinggi. Relay bekerja dengan memberikan energi listrik pada koil sehinga koil dapat menggerakkan kontak.

Konfigurasi dari kontak-kontak relay terdiri dari normally open (NO) dan normally close (NC). Kontak normally open akan membuka ketika 
tidak ada arus mengalir pada kumparan, tetapi tertutup secepatnya setelah koil dialiri arus listrik. Kontak normally close akan menutup kontak apabila tidak ada arus yang mengalir pada koil dan membuka ketika koil dialiri arus listrik.

\section{METODOLOGI PENELITIAN}

Pada perancangan Prototype pembatas biaya daya listrik ini terdiri dari dua bagian yaitu perancangan perangkat keras dan perancangan perangkat lunak.

\subsection{Blok Diagram Sistem}

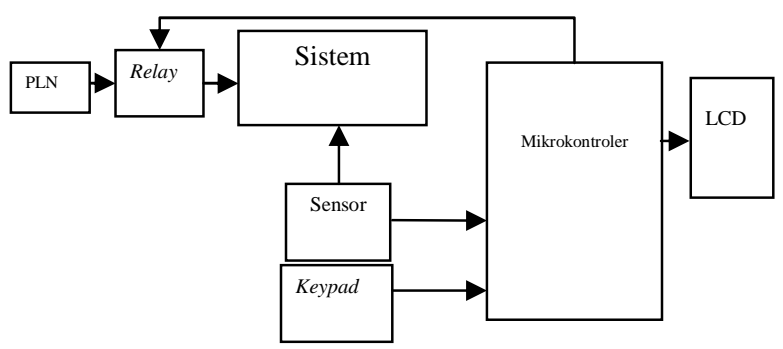

Gambar 3.1 Blok Diagram Sistem.

\subsection{Perancangan Perangkat Keras}

\section{a. Pengendali Utama}

Sistem pengendali utama yang digunakan dalam prototipe pembatas biaya listrik adalah mikrokontroler 8 bit.

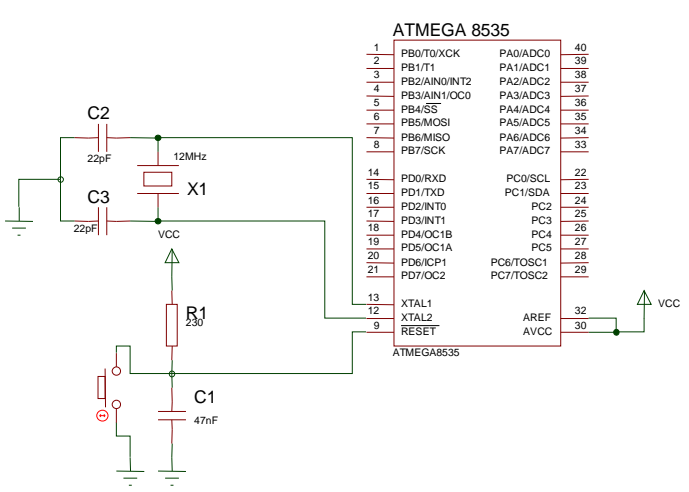

Gambar 3.2. Rangkaian sistem minimum mikrokontroler.
Mikrokontroler 8 bit memilki EEPROM (Electrically Erasable Programable Read-Only Memory), yaitu sejenis chip memori yang bisa menyimpan data seacara permanen, dan kemudian bisa dihapus atau dituliskan kembali dan digunakan dalam suatu aplikasi peralatan elektronik untuk menyimpan sejumlah kecil konfigurasi data pada alat elektronik tersebut.

\section{b. Liquid Crystal Display (LCD)}

Komponen elektronik yang digunakan sebagai modul tampilan informasi dalam mendeteksi arus ini adalah LCD (Liquid Crystal Display) 2x16. LCD ini diprogram melalui mikrokontroler agar dapat menampilkan informasi pemakaian $\mathrm{kWh}$ dan biaya listrik yang ditentukan. Gambar 3.4 menunjukkan bentuk rangkaian skematik dari LCD $2 \times 16$.

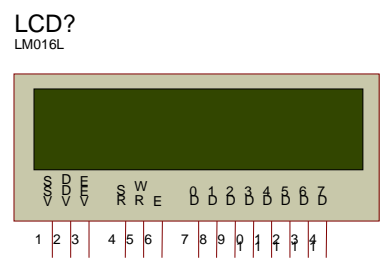

Gambar 3.3. Rangkaian LCD.

c. Sensor Arus

Sensor arus adalah sensor yang digunakan untuk mendeteksi dan mengukur arus pada sistem AC dengan kemampuan arus sampai 20 A [5]. Hasil pembacaan arus ini diolah oleh ADC mikrokontroler dan keluaran nantinya ditampilkan pada LCD 2x16.

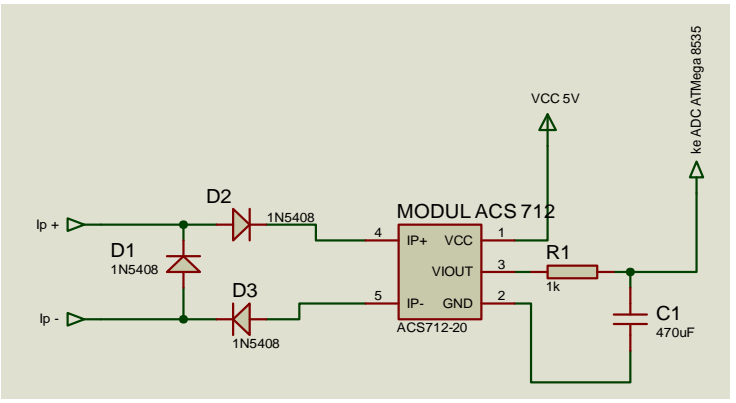

Gambar 3.4 Skematik rangkaian sensor arus. 


\section{d. Rangkaian Relay.}

Pada rangkaian relay merupakan output dari mikrokontroler. Mikrokontroler akan mengolah biaya daya listrik yang dibutuhkan, apabila biaya sudah sesuai yang diinginkan, maka mikrokontroler akan memerintah relay dengan mengeluarkan tegangan sebesar $5 \mathrm{~V}$ sehingga relay akan aktif (NC) sehingga sistem dalam arus $\mathrm{AC}$ akan mati.

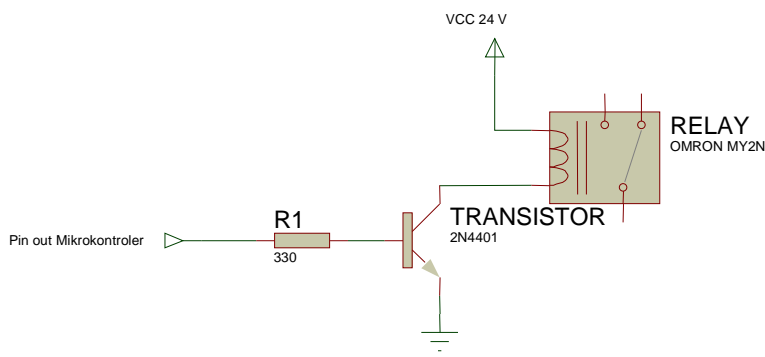

Gambar 3.5 Skematik rangkaian relay

e. Rangkaian Power supply.

Power supply dalam penelitian tugas akhir ini digunakan untuk mengubah tegangan AC menjadi tegangan DC. Tegangan DC dari power supply digunakan untuk memberi daya pada rangkaian prototipe pembatas biaya daya listrik.

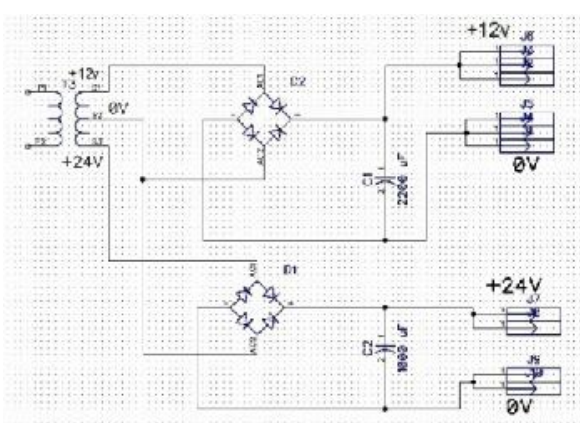

Gambar 3.6 Rangkaian skematik Power Supply

\subsection{Perancangan Perangkat Lunak}

Dalam tugas akhir ini, penulis menggunakan pemrograman bahasa $\mathrm{C}$ yang ditulis melalui software bahasa $\mathrm{C}$ untuk mengendalikan hardware. Bahasa pemrograman yang digunakan kemudian di-download mikrokontroler.

Adapun langkah-langkah dalam perancangan perangkat lunak dapat dilihat pada Gambar 3.6 berikut:

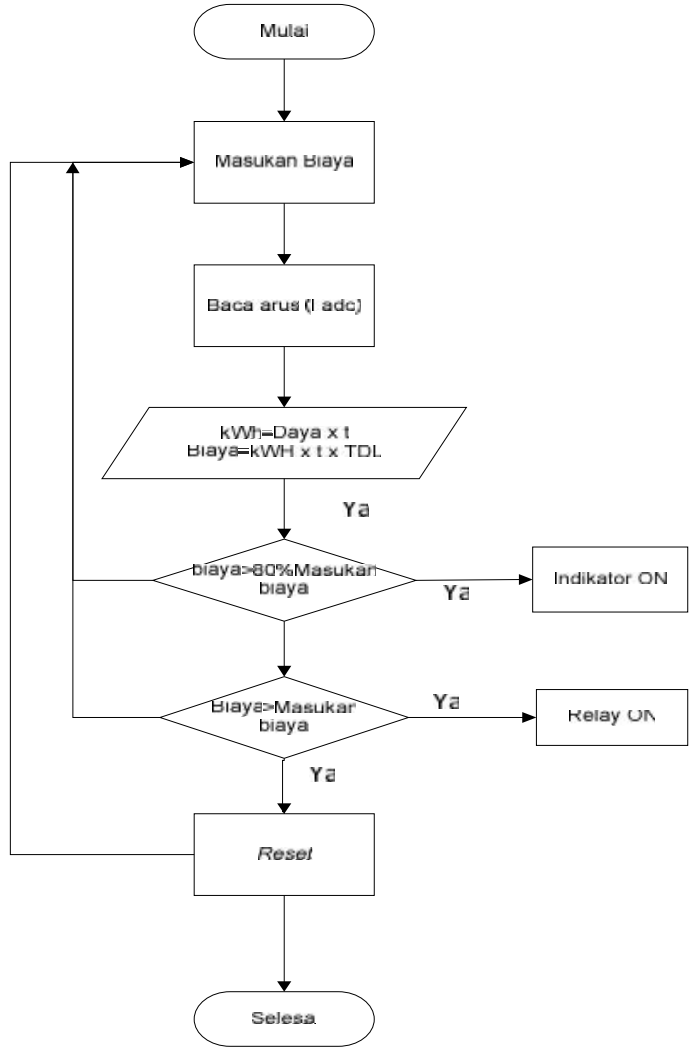

Gambar 3.7 Flowchart perancangan perangkat lunak.

\section{HASIL DAN PEMBAHASAN}

Pengujian sistem dilakukan bertujuan untuk mengetahui kinerja dan kemampuan dari perangkat yang dibangun. Pengujian dilakukan pada masing-masing subsistem dari perangkat, sehingga dapat dianalisa dan disimpulkan apakah perangkat telah sesuai dengan yang diharapkan.

\subsection{Pengujian Perangkat Keras}

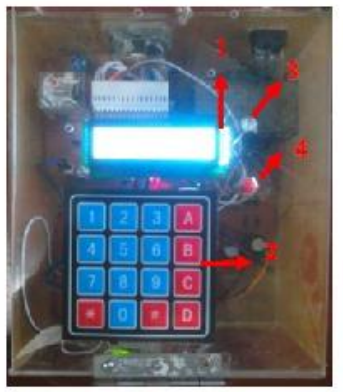

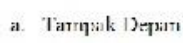

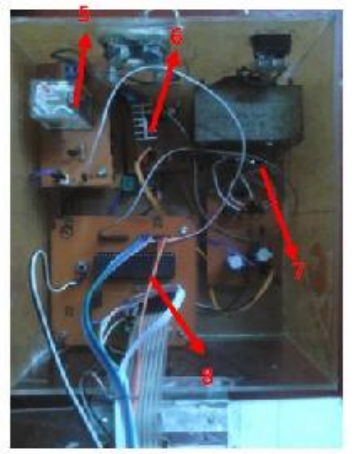

P. Tarm pak Isilam
Gambar 4.1 Pembatas biaya daya listrik 
Keterangan gambar :
1. LCD
5. Rangkaian relay
2. Keypad
6. Rangkaian sensor arus
3. Indikator
4. Reset
7. Rangkaian power supply
8. Pengendali utama.

\section{a. Mikrokontroler sebagai pengendali utama}

Pengujian terhadap pengendali utama bertujuan untuk mengetahui apakah mikrokontroler dapat bekerja dengan baik atau tidak. Adapun pengujiannya adalah dengan mengecek pin-pin input dan pin-pin output yang ada pada mikrokontroler.

Untuk mengetahui apakah pin-pin tersebut dapat bekerja dengan baik adalah dengan mengukur tegangan pada pin-pin tersebut. Apabila mikrokontroler diberikan logika high, tegangan yang terukur sekitar 4,5-5,5 V. Dan apabila diberikan logika low, tegangan yang terukur mendekati $0 \mathrm{~V}$. Pengujian pada mikrokontroler dilakukan dengan mengambil satu pin yaitu mengukur tegangan pada PA1, PB2, PC5, dan PD7.

Tabel 4.1 Hasil pengujian pengukuran tegangan pada mikrokontroler.

\begin{tabular}{|c|c|cc|c|}
\hline Logika & $\begin{array}{c}\text { Tegangan } \\
\text { P'Al }\end{array}$ & $\begin{array}{c}\text { Tegangan } \\
\text { P'B2 }\end{array}$ & $\begin{array}{c}\text { Tegangan } \\
\text { P'C5 }\end{array}$ & $\begin{array}{c}\text { Tegangan } \\
\text { P'D7 }\end{array}$ \\
\hline High & $4,53 \mathrm{~V}$ & $4,65 \mathrm{~V}$ & $4,52 \mathrm{~V}$ & $4,54 \mathrm{~V}$ \\
\hline Low & $0,07 \mathrm{mV}$ & $0,08 \mathrm{mV}$ & $0,07 \mathrm{mV}$ & $0,07 \mathrm{mV}$ \\
\hline
\end{tabular}

\section{b. Rangkaian Power Supply}

Pengujian power supply bertujuan untuk mengetahui apakah tegangan yang dihasilkan oleh power supply sesuai dengan yang diinginkan atau tidak. Rangkaian power supply menghasilkan tegangan output sebesar +12 Volt DC dan +24 Volt.

Keluaran Power supply dengan tegangan +12 Volt digunakan untuk rangkaian sensor arus ACS dan mikrokontroler dimana pada masing-masing rangkaian ini telah memiliki IC regulator LM7805 sehingga keluaran yang dihasilkan menjadi $+4,96$ Volt. Keluaran Power supply dengan tegangan +24 Volt digunakan untuk rangkaian relay.

\section{c. Rangkaian Sensor Arus}

Prinsip kerja sensor arus mendeteksi dan mengukur arus pada listrik arus bolak-balik yang digunakan. Pada saat listrik tanpa beban, maka sensor akan mengeluarkan output 2,5 V. Sesuai dengan datasheet, pada saat penambahan arus atau beban listrik maka output sensor ACS akan bertambah secara linier. Kenaikan output sensor arus yaitu $100 \mathrm{mV}$ per Ampere.

Sensor arus dapat mengukur arus bolak-balik dan arus searah. Jika arus yang diukur arus searah maka keluaran dari sensor arus adalah tegangan searah dan jika arus yang diukur arus bolak-balik maka tegangan keluaran sensor arus adalah tegangan bolak-balik.

Tabel 4.2 Hasil pengujian sensor arus.

\begin{tabular}{|c|c|c|}
\hline Bcban & Anus Multimctcr (A) & $\begin{array}{c}\text { Tegangan Scnsor } \\
\text { Arus (V) }\end{array}$ \\
\hline Tanpa beban (0) & 0,002 & 2,484 \\
\hline 1 laupu (100 W) & 0,123 & 2,503 \\
2 lampu (200 W) & 0,854 & 2,522 \\
\hline 3 lampu (300 W) & 1,278 & 2,541 \\
setrika (350 W) & 1,582 & 2,551 \\
\hline 1 lampu + setrika (450W) & 2,012 & 2,571 \\
\hline 2 lampu + setrika (550 W) & 2,483 & 2,590 \\
\hline 3 lampu I sctrika (650 W) & 2,942 & 2,611 \\
\hline
\end{tabular}

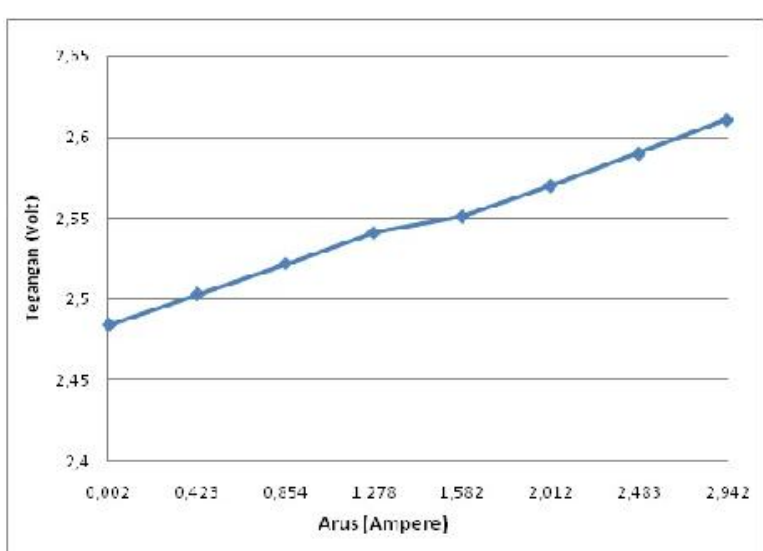

Gambar 4.1 Grafik hubungan antara Arus terhadap perubahan tegangan output dari sensor arus.

Pada gambar dapat dilihat grafik perbandingan arus yang dideteksi oleh sensor dengan tegangan keluaran sensor. Pada grafik terlihat bahwa arus dan tegangan berbanding lurus. Semakin tinggi besar arus yang dideteksi oleh sensor maka semakin besar tegangan keluaran dari sensor arus. 


\section{d. Pengujian LCD}

Pengujian pada LCD dilakukan dengan cara menghubungkan masing-masing pin pada LCD yang ke sistem minimum mikrokontroler.

Tabel 4.3 Fungsi pin pada LCD yang terhubung dengan mikrokontroler.

\begin{tabular}{|c|c|c|}
\hline Pin & Fungsi & Komponen Lain \\
\hline 1 & Ground & ground \\
\hline 2 & $\begin{array}{l}\text { Kaki untuk masukan } \\
\text { tegangan }\end{array}$ & $\begin{array}{c}\text { Titik } 5 \text { Volt pada power } \\
\text { supply }\end{array}$ \\
\hline 3 & Pengatur kekontrasan & $\begin{array}{l}\text { Ground (kontras selalu } \\
\text { maksimal) }\end{array}$ \\
\hline 4 & Register Select Signal & PB0 pada mikrokontroler \\
\hline 5 & Read/Write Signal & PB1 pada mikrokontroler \\
\hline 6 & Enable Signal & PB2 pada mikrokontroler \\
\hline 7 & Jalur bus data & - \\
\hline 8 & Jalur bus data & - \\
\hline 9 & Jalur bus data & - \\
\hline 10 & Jalur bus data & - \\
\hline 11 & Jalur bus data & PB4 pada mikrokontroler \\
\hline 12 & Jalur bus data & PB5 pada mikrokontroler \\
\hline 13 & Jalur bus data & PB6 pada mikrokontroler \\
\hline 14 & Jalur bus data & PB7 pada mikrokontroler \\
\hline 15 & $\begin{array}{l}\text { Tegangan keluaran } \\
\text { negatif }\end{array}$ & $\begin{array}{c}\text { Titik } 5 \text { volt pada power } \\
\text { supply }\end{array}$ \\
\hline 16 & Ground & $\begin{array}{l}\text { Titik ground pada power } \\
\text { supply }\end{array}$ \\
\hline
\end{tabular}

Setelah kaki-kaki LCD terhubung, pengendali utama diprogram untuk menampilkan karakter. Apabila karakter yang ditampilkan pada LCD sesuai dengan karakter yang diprogram pada mikrokontroler, maka LCD bekerja dengan baik.

\section{e. Rangkaian Relay}

Pengujian relay ini dilakukan untuk mengetahui apakah relay bekerja sesuai dengan yang ditentukan.

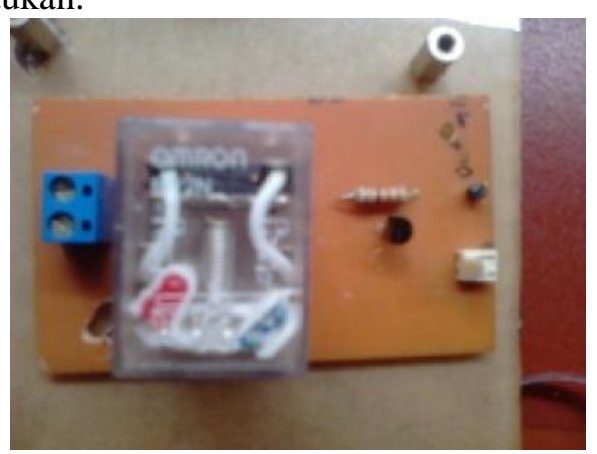

Gambar 4.2 Rangkaian relay

Gambar 4.8 merupakan rangkaian relay, dimana output dari mikrokontroler akan diteruskan ke relay melalui sebuah transistor. Transistor didalam rangkaian relay berfungsi sebagai switch.
Dengan memampaatkan karakteristik transistor emitor bersama, pada kondisi saturasi (jenuh) dan keadaan cut-off (mati) maka transistor dapat dijadikan saklar dengan pemutus dan menyambungnya berupa tegangan pada basisnya. Pada saat kondisi saturasi, transistor menjadi saklar sehingga arus mengalir dari kolektor menuju emitor. Jika kondisi cut off transistor berfungsi sebagai saklar penutup karena tidak ada arus yang mengalir dari kolektor ke emitor.

Pada saat output dari mikrokontroler sebesar $0 \mathrm{~V}$ maka transistor akan berfungsi sebagai saklar posisi mati maka relay pada rangkaian ini beerada pada kondisi off. Sebaliknya jika output dari mikrokontroler sebesar 5 volt maka transistor akan berfungsi sebagai saklar posisi on maka relay pada rangkaian ini akan berada pada kondisi on. Relay yang dipakai adalah OMRON MY2N dimana relay ini bisa memutus arus dengan kemampuan sampai 5A AC.

\subsection{Pengujian Perangkat Lunak}

Pengujian perangkat lunak sebagai berikut : Program pembacaan ADC dari sensor arus.

a. Membaca ADC pada port 2

Membuat ADC Mikrokontroler yaitu 10 bit.

b. Penghitungan $\mathrm{kWh}$ pemakaian listrik terpakai.

Perhitungan ini digunakan dengan timer 10 bit. Pada alat ini pembacaan arus pada sensor dilakukan setiap 5 detik agar dapat mendeteksi dengan cepat apabila ada perubahan arus sehingga perhitungan dalam mencari $\mathrm{kWh}$ nya semakin akurat. Hasil pemakaian $\mathrm{kWh}$ nya akan ditampilkan ke LCD setiap 5 detik, dimana digunakan rumus $\mathrm{kw} 1=\mathrm{kwh}+\mathrm{kwh} 1$. KWh yang dihitung oleh mikrokontroler ditambahkan dengan $\mathrm{kWh}$ baru yang dihitung setiap 5 detik oleh mikrokontroler.

c. Perhitungan pemakaian biaya listrik.

Perhitungan biaya dihitung setiap 5 detik. Blok merupakan harga dari biaya listrik per blok. Perhitungan harga menggunakan rumus biaya1=biaya+biaya1. Dimana biaya yang dihitung oleh mikrokontroler ditambahkan dengan biaya baru yang dihitung setiap 5 detik oleh mikrokontroler. 
d. Program perintah indikator LED dan Relay.

Biayal merupakan biaya yang yang sedang dihitung, pengali merupakan 80 persen dari nilai yang di input pada keypad. Jadi jika biaya lebih besar 80 persen dari pengali maka PORT.B akan memberi logika high yang memerintah relay untuk menghidupkan indikator.

Biaya1 merupakan biaya yang sedang dihitung, nilai merupakan biaya yang di input pada keypad. Jadi jika biaya lebih dari nilai maka PORTB.4 akan memberi logika high yang memerintah relay untuk memutus pemakaian listrik.

\subsection{Pengujian Sistem}

Pengujian sistem ini adalah pengujian terhadap gabungan perangkat keras dan perangkat lunak. Pengujian pada sistem dilakukan dengan tujuan untuk mengetahui apakah alat yang digunakan dapat bekerja secara maksimal atau tidak. Tahap awal pembuatan alat ini adalah dengan memprogram mikrokontroler 8 bit sebagai pengendali utama. Program-program awal untuk menguji komponen seperti sensor arus, keypad, LCD dan relay dan digabungkan sehingga membentuk sebuah perangkat lunak yang telah dibuat terprogram ke mikrokontroler. Kemudian komponen-komponen tersebut yang berupa power supply, sensor arus, LCD dan relay dihubungkan ke mikrokontroler. Konfigurasi penempatan sensor pada kaki IC mikrokontroler sebagai berikut:

1. Port A.2 disetting sebagai masukan mikrokontroler yang berasal dari keluaran sensor arus.

2. Port B.2 disetting sebagai keluaran dari mikrokontroler yang menjadi masukan bagi rangkaian LED.

3. Port B.4 disetting sebagai keluaran dari mikrokontroler yang menjadi masukan bagi rangkaian relay.

4. Port $\mathrm{D}$ disetting sebagai masukan dari mikrokontroler yang menjadi keluaran bagi keypad.

Port $\mathrm{C}$ disetting sebagai keluaran dari mikrokontroler yang menjadi masukan bagi rangkaian LCD.
Tabel 4.4 Pengujian sistem

\begin{tabular}{|c|c|c|c|c|c|c|c|c|}
\hline $\begin{array}{l}\text { Biaya } \\
(\mathrm{Rp})\end{array}$ & Daya (Watt) & $\begin{array}{l}\text { I } \\
\text { LCD } \\
\text { (A) }\end{array}$ & $\begin{array}{l}\text { I } \\
\text { Multi } \\
\text { meter } \\
\text { (A) }\end{array}$ & $\begin{array}{l}\mathrm{kWh} \\
\mathrm{LCD} \\
(\mathrm{kW})\end{array}$ & $\begin{array}{l}\text { Ciata } \\
\text { relatif } \\
\text { aris } \\
(\%)\end{array}$ & $\begin{array}{c}\text { Waktu } \\
\text { remuntusan } \\
\text { listrik } \\
\text { (pengukuran) }\end{array}$ & $\begin{array}{c}\text { Walilu } \\
\text { permutusan } \\
\text { listrik } \\
\text { (perhiturgan) }\end{array}$ & $\begin{array}{l}\text { Gala: } \\
\text { relatif } \\
\text { waktu } \\
(\%)\end{array}$ \\
\hline 500 & $\begin{array}{l}100 \\
(5 \operatorname{lompm})\end{array}$ & 0.46 & 0,423 & 1,81 & 8,7 & $\begin{array}{l}17 \text { jam } 58 \text { menit } \\
37 \text { detik }\end{array}$ & $\begin{array}{l}18 \mathrm{jam} 10 \\
\text { uemil S1 detik }\end{array}$ & 1,9 \\
\hline 500 & $\begin{array}{l}200 \\
\text { (2 lampu) }\end{array}$ & 0,86 & 0,854 & 1,81 & 0,7 & $\begin{array}{l}9 \text { jam } 37 \text { menit } \\
\text { sdctik }\end{array}$ & $\begin{array}{l}9 \text { jam } 5 \text { menit } \\
24 \text { dctik }\end{array}$ & 5,7 \\
\hline 500 & $\begin{array}{l}300 \\
\text { (3 lampu) }\end{array}$ & 1,32 & 1,278 & 1,81 & 3,2 & $\begin{array}{l}6 \text { jam } 15 \text { menit } \\
\text { 3dctik }\end{array}$ & $\begin{array}{l}6 \mathrm{jam} 3 \text { menit } \\
36 \mathrm{det} \text { tik }\end{array}$ & 3,1 \\
\hline 500 & $\begin{array}{l}350 \\
\text { (setrika } 350 \\
\text { w) }\end{array}$ & 1,57 & 1,582 & 1,81 & 0,7 & $\begin{array}{l}8 \mathrm{Jam} 46 \text { menit } \\
16 \text { detik }\end{array}$ & $\begin{array}{l}9 \text { jam } 10 \text { memi } \\
51 \text { detik }\end{array}$ & 4,5 \\
\hline 500 & $\begin{array}{l}150 \\
\text { (setrika 350W } \\
\text { - Hampu } \\
\text { 100W) }\end{array}$ & 1,99 & 2,012 & 1,81 & 1,9 & $\begin{array}{l}5 \text { Jann } 48 \text { aczuit } \\
27 \text { detik }\end{array}$ & $\begin{array}{l}6 \text { jam } 1 \text { menit } \\
30 \text { detik }\end{array}$ & 3,3 \\
\hline 500 & $\begin{array}{l}550 \\
\text { (setika 350W } \\
+2 \text { lamapu } \\
\text { 100W) }\end{array}$ & 2,56 & 2,483 & 1,81 & 3,1 & $\begin{array}{l}4 \text { Jum } 04 \text { mecril } \\
41 \text { detik }\end{array}$ & $\begin{array}{l}4 \text { jam } 29 \text { mcnit } \\
52 \text { detik }\end{array}$ & 1,0 \\
\hline 500 & $\begin{array}{l}650 \\
\text { (setrika 350W } \\
+3 \text { lawapu } \\
100 \mathrm{~W} \text { ) }\end{array}$ & 3,01 & 2,942 & 1,81 & 2,3 & $\begin{array}{l}2 \text { jumn } 44 \text { menil } \\
25 \text { retik }\end{array}$ & $\begin{array}{l}3 \text { jam } 35 \text { menit } \\
13 \text { detike }\end{array}$ & 2,3 \\
\hline
\end{tabular}

\section{SIMPULAN DAN SARAN}

\subsection{Simpulan}

Dari pembahasan dan analisis pada bab-bab sebelumnya, dapat disimpulkan bahwa:

1. Prototipe pembatas biaya listrik otomatis dapat bekerja dengan baik menampilkan besarnya pemakaian arus dengan persen kesalahan rata-rata sebesar 2,95.

2. Prototipe pembatas biaya listrik otomatis ini dapat bekerja dengan baik memutus pemakaian listrik jika nilainya melebihi batas biaya pemakaian yang diinginkan dengan persen kesalahan rata-rata sebesar 3,54.

3. Prototipe pembatas biaya listrik ini dapat mengefisienkan dan mengontrol penggunaan listrik pada rumah tangga.

\subsection{Saran}

Adapun saran dari penelitian ini adalah sebagai berikut :

1. Penelitian selanjutnya sebaiknya menggunakan sensor tegangan agar perhitungan $\mathrm{kwh}$ sesuai dengan tegangan listrik yang sedang berlangsung.

2. Tingkat akurasi alat dalam mendeteksi arus sangat sensitif terutama dalam mengukur arus yang kecil sehingga dibutuhkan rangkaian tambahan. 


\section{DAFTAR PUSTAKA}

[1] B.L Theraja, A.K Theraja. A Textbook Of Electrical Technology, S. Chand \& Company ltd, New Delhi, First Multicolour Edition. 2005.

[2] Khakim, Lukmanul. Pembuatan Alat penghemat Energi Listrik pada Lampu High Pressure Lamp ( HPL ). Tugas Akhir. Politeknik Negri Semarang. 2010.

[3] Permen. Peraturan Menteri Energi dan Sumber Daya Mineral. Jakarta. 2012.

[4] Fitriastuti, F dan Siswadi. Aplikasi $\mathrm{KwH}$ (Kilo What Hour) Meter Berbasis Microntroller Atmega 32 Untuk Memonitor Beban Listrik. Jurusan Teknik Informatika. Universitas Janabadra. 2011.

[5] Allegro. ACS706ELC-20A, Bidirectional $1.5 \mathrm{~m}$ Hall Effect Based Linear Current Sensor with Voltage Isolation and $20 \mathrm{~A}$ Dynamic Range, Worcester, Allegro Micosystems,Inc. Diakses pada tanggal 3 Juni 2013. http:// www.allegromicro.com 